\title{
A comunicação interna no verso e no anverso
}

s pessoas se comunicam. Ponto. Essa afirmação tem tanta
verdade quanto o desejo de exercer algum controle sobre
esses momentos comunicativos. Desde que o mundo existe, desde as mais rupestres comunicações, os seres humanos precisam entabular entre si codificações que lhes permitam o convívio. Esta revista, é claro, volta-se a essa convivência no ambiente corporativo, naquele em que as regras estão estabelecidas, mesmo que elas não sejam ditas.

E como viver/conviver/sobreviver em um ambiente em que as coisas nem sempre estão claras? As codificações da comunicação organizacional nos ambientes internos das organizações são tão ou mais complexas do que aquelas encontradas nos espaços extramuros. Se entre organizações e seus parceiros (fornecedores, clientes, governo, comunidade etc.) há a extrema necessidade de se aclararem intenções e possibilidades, nos ambientes ditos internos - e sobre essa internalidade caberá comentário mais adiante - é comum acreditar que o simples convívio possa aclarar as tais intenções e possibilidades de comunicação. E assim pode-se chegar ao risco, à comunicação de risco. Não apenas por estarmos em tempos de mudança no comportamento social, com tecnologias que "furam" as notícias, com novas regras de relacionamento, mas principalmente porque a comunicação interna ganha fôlego, energia: é entendida como diferencial no processo do fazer e do fazer melhor.

As organizações e suas comunicações são porosas. Informações vazam, extravasam, permeiam relacionamentos e rituais ganham novos significados. 0 que se passa formal e informalmente no ambiente externo impacta de modo direto o que se viverá no espaço interno. E o contrário não é menos verdadeiro: a comunicação dos funcionários, empregados, colaboradores ou como quer que os chamemos e seus significados, vai embarcada em produtos e serviços, gerando noção de valor - tanto positivo quanto negativo, cabe dizer. 
O tempo real écada vez mais verdadeiro, sem trocadilhos, porque as pessoas se empoderam de instrumentos e conhecimentos que permitem avaliar de dentro para fora o que as organizações fazem também de fora para dentro. 0 desejo humano de exercer controle sobre os outros, sobre as emanações significativas, sobre as manifestações culturais, sobre o pensamento não deixaram de existir. Apenas podemos crer que estejamos vivendo um tempo em que essa troca simbólica - considerando o ciberespaço mais próximo, informal, graficamente bem cuidado, aberto, opinativo e emocional, quase visceral - ganha adeptos e se qualifica.

Se em um tempo anterior se pensava sobre as ferramentas, sobre os tempos e movimentos, hoje viabiliza-se a interação que faz diferença na percepção sobre o que cada empresa "vende" como sendo a sua realidade. Ou por que tantas organizações comunicariam o seu DNA atualmente? Porque a origem ou a essência se dá exatamente pela realidade que cada pessoa expressa pelas suas ações cotidianas. E a antropomorfização organizacional é a tentativa de se tornar mais próxima.

A comunicação interna, então, ganha relevo, destaque e investimento. Este número 19 de nossa revista é uma reflexão sobre esse campo tão importante e que estabelece pilares para a sustentação de todas as organizações e que ao mesmo tempo realiza um trabalho silencioso de relações públicas, consolidando relacionamentos a partir dos próprios relacionamentos. Se eles se consolidam no ambiente interno, a sua reverberação será segura para outros espaços e potencializará relacionamentos melhores e mais firmes.

A temática central, "Comunicação interna: processos e as interações nas organizações", ganha corpo na seção propriamente dita do Dossiê, com nove artigos capazes de fomentar a discussão sobre a comunicação interna, sua importância, suas estratégias, seus processos e suas ferramentas.

A pesquisadora espanhola María Carmen Carretón Ballester nos apresenta os seus estudos sobre a contribuição das práticas de responsabilidade social na eficácia das estratégias de comunicação interna, no texto "La comunicacion en la responsabilidad social interna". Wilson Bueno, em seu artigo "Comunicação interna e liderança aberta: os desafios de incorporar a geração Y e as mídias sociais", coloca foco na entrada dessa nova geração no mercado de trabalho e o seu impacto na comunicação organizacional interna, com relação à qual sustenta a urgência de uma nova postura no modelo de gestão de pessoas a fim de favorecer a construção de um ambiente organizacional mais saudável e contemporâneo. Ana Luísa de Castro Almeida, Rozália Del Gáudio Soares Baptista e Paulo Henrique Leal Soares, em "Comunicação interna e redes sociais: desafios e possibilidades no relacionamento com os empregados", refletem sobre o uso adequado das redes sociais nas organizações, destacando as dimensões de coerência e responsabilidade como imperativos nesse contexto, principalmente em ambientes ainda marcados pelas prerrogativas de centralização e controle típicas da gestão. Angela C. Salgueiro Marques e Rennan L. M. Mafra discutem a importância da compreensão do diálogo não apenas como caminho para harmonização das interlocuções organizacionais, mas como um "processo dissensual" fundamental para um ambiente efetivo de trocas e resolução de problemas e conflitos, no texto "Diálogo no contexto organizacional e lugares de estratégia, argumentação e resistência". Kátia Perez, em seu artigo "Espaço de interação nas empresas: os lugares da comunicação formal face a face", explora as oportunidades de espaços disponíveis na organização para o estabelecimento de interações - não quaisquer interações, mas interações com significado, potencializando o uso da comunicação face a face. E 0 artigo de Ary J. Rocco Junior, "A comunicação interna e a construção da cultura organizacional em equipes esportivas vencedoras: o caso do FC Barcelona", explora a relevância do planejamento estratégico da comunicação nas organizações esportivas. 
Ainda na seção do Dossiê, "Uma nova visão sobre a informação que circula internamente nas organizações em tempo de TIDC's", da pesquisadora Enoí Dagô Liedke, apresenta uma proposta de conceituação para a informação que circula entre o público interno organizacional, revisitando e tipificando os fluxos e as redes, por considerar que o melhor entendimento sobre os novos elementos da comunicação na era da comunicação digital pode auxiliar o comunicador na definição de sua estratégia de comunicação. 0 artigo do mexicano Fernando Adame, "Los procesos del PGC de Nosnik: herramienta útil en el analisis de problemas de comunicación interna", debruça-se sobre os conceitos nosnikianos de "plano geral de comunicação" e "processo de comunicação gerencial" para a solução de problemas de comunicação interna. Cynthia Sganzerla Provedel, em "Perspectiva teórica da comunicação compreensiva: um novo olhar interpretativo para a comunicação interna", encerra o dossiê propriamente dito, explorando a questão dos medos e dos boatos no contexto organizacional e a relevância de se tratar as emoções nesse cenário.

Mas a temática do dossiê se vê estendida em outras seções da revista, ganhando uma rica dimensão, por exemplo, com a entrevista sobre "A força de uma comunicação interna bem planejada", concedida à professora Valéria Cabral por um grande especialista no tema: o professor Joel Dutra, diretor de Recursos Humanos da Universidade de São Paulo, livre-docente em Administração no tema gestão de pessoas e um dos coordenadores, desde 2006, da avaliação da pesquisa "As melhores para trabalhar", publicada anualmente pela revista Você $S / A$, da Editora Abril. Na entrevista, Joel compartilha com os leitores de Organicoma importância que detém a comunicação interna bem planejada na consecução eficaz dos resultados alcançados pelas "melhores". A entrevista se complementa de alguma forma com dois depoimentos de outros executivos do mercado profissional. Hélio Muniz, diretor de Comunicação do McDonald's no Brasil, numa linguagem agradável, com reflexões claras e muito pertinentes, mostra como a comunicação interna tem "Infinitas possibilidades com o segredo do tempero local". 0 segundo depoimento, muito completo e valioso, é de Gilceana Galerani, chefe da Secretaria de Comunicação (Secom) da Embrapa (Brasília) e Aline Bastos, supervisora de Relacionamento com o Público Interno na mesma Secom, que nos apresentam a experiência bem-sucedida dessa instituição com a "Comunicação interna estratégica".

A temática do dossiê permeia ainda alguns artigos da seção Pesquisa, onde se reproduzem resultados de trabalhos de campo. Essa seção reúne quatro consistentes trabalhos consonantes com a busca de melhor entendimento e do aprofundamento necessário que merece e requer a temática da comunicação interna para uma abordagem estruturada e fundamentada nas organizações.

Nesse sentido, considerando o engajamento como palavra de primeira linha para se garantirem resultados superiores, tem, muito interesse a contribuição da pesquisadora Ana Cristina Fachinelli, sintetizada no artigo "Informação, comunicação e comprometimento: um desafio para o engajamento do público interno", onde ela busca associar claramente os níveis de satisfação com a comunicação e o grau de envolvimento dos empregados com os resultados das empresas por ela pesquisadas. E, já que a comunicação interna envolve diálogo, é muito expressivo o trabalho de pesquisa de Marta T. Martins, que apresenta um recorte de sua tese de doutorado sobre manifestações e usos da fala, observada nas interações entre gestores e empregados de uma estatal do norte do Paraná, no artigo "Diálogo e interações face a face: a força da oralidade na comunicação interna". Ivone de Lourdes Oliveira e Terezinha Gislene Rodrigues Alencar, no texto "Dinâmica comunicativa no ambiente interno das organizações: inter-relação da comunicação formal com a comunicação informal", demonstram, com base em pesquisa empírica, a interdependência entre esses dois processos interativos no ambiente interno das organizações. Por fim, em "A pequena empresa brasileira e suas demandas comunicacionais internas: amadorismo, fluxos, vaidade", Wellington Teixeira Lisboa e Fernanda Portes Alves apresentam um interessante estudo sobre a gestão dos relacionamentos para o sucesso de um pequeno negócio. 
A temática do Dossiê sobre comunicação interna, finalmente, é explorada também em quatro das cinco resenhas reproduzidas nesta edição: "A comunicação interna além do discurso", assinada por Patrícia Salvatori; "Gestão da comunicação interna: tarefa fácil?", assinada por Valéria de Siqueira Castro Lopes; e "O público interno como ponto de partida para a excelência na comunicação organizacional", assinada por Valéria Aparecida Cabral. Esta última também assina a resenha "A metodologia Great Place to Work - GPTW", explorando sumariamente o livro A melhor empresa para trabalhar: como construí-la, como mantê-la e por que isso é importante, de Michael Burchell e Jennifer Robin, lançado no Brasil em 2012, com o selo da Editora Bookman.

Não abordando expressamente a temática do Dossiê, esta edição de Organicom traz na seção Espaço Aberto três textos fundamentais para uma reflexão oportuna sobre valores como cidadania, ética e resiliência (que trata sobre a capacidade inerente ao ser humano de se recompor após alguma situação crítica, tão importante em tempos permanentes de mudança). Em "Comunicação pública e comunicação política: por uma interação entre cidadania e democracia", Heloiza Helena Matos e Nobre e Guilherme Fráguas Nobre defendem esse posicionamento a partir de seis varáveis inter-relacionadas: capital social, capital comunicacional, comunicação pública, comunicação política, cidadania e democracia. "A ética como fator de suporte ao discurso da sustentabilidade nas organizações", de Ana M. de Maio e Marcelo da Silva propõe a ética na comunicação organizacional como um mecanismo de sustentabilidade na construção do discurso organizacional, considerando a abordagem de Gilles Lipovetsky. Por fim, fechando essa seção, Roberto José Ramos e Fernanda Lopes de Freitas, com o artigo "Resiliência e relações públicas: diálogos e reflexos, apresentam uma abordagem, no âmbito das relações públicas, do conceito resiliência, originário da física.

Para finalizar este editorial, há de se assinalar ainda que, na seção Pesquisa, merece destaque também o artigo "As estratégias de comunicação da marca Rio em eventos de alta visibilidade: o caso da Rio+20", no qual Paulo Roberto Nassar de Oliveira e Patrícia Cerqueira Reis argumentam que a "marca" de uma cidade não pertence a um único ente, mas à cidade, vista como instituição, e a todos aqueles que a compõem e a consomem nos mais variados aspectos presentes no cotidiano. E, ainda, na seção de Resenhas, o texto "Comunicação pública e cidadania crítica", com Francine Altheman apresentando a obra Comunicação pública: interlocuções, interlocutores e perspectivas, organizada por Heloiza Matos, que traz contribuições importantes, suprindo uma carência existente na área e fomentando o interesse de novos pesquisadores.

Suprir carências e despertar o interesse pela pesquisa é, aliás, o objetivo de tudo o que se expõe nesta edição de Organicom. Por isso, nossos votos são de que sua leitura seja não somente agradável, mas, sobretudo, proveitosa. 